\title{
A Study on the Influence of Motivation on Open University Students' Vocabulary Attrition
}

\author{
Huang Yu, Zhou Shu \\ Si Chuan Open University
}

\begin{abstract}
This research aims to explore English language attrition experienced by students of Nan Chong Open University. The main purpose of this research is to examine whether students undergo attrition during a two-month break from English language instruction. Through empirical study, this research attempts to arrive at propositions which account for the language attrition that takes place among the EFL, students in China so that the attrition problem might be shed light on and alleviated.
\end{abstract}

Keywords: vocabulary attrition; motivation; influence; Open University students

\section{INTRODUCTION}

Language attrition, which is generally considered the decrease in language skills proficiency, has gained importance in research and caught many scholars' attention since the Conference on the Attrition of Language Skills held at the University of Pennsylvania in 1980. In that conference, language attrition was broadly defined as the loss of any language or any portion of a language by an individual or a speech community (Freed, 1982); it may refer to the declining use of mother tongue skills by those in bilingual situations or among ethnic minorities, or it also refers to the deterioration of language skills in neurologically impaired patients and to the decline of certain types of language usage by the elderly. Since vocabulary learning is one of the most important part of English learning, vocabulary attrition becomes accordingly the focus of English language attrition research and is carried out the most frequently one in the field. Olstain (1989) investigated thirty Hebrew children's English attrition where Hebrew is the dominant language. He found the preposition category suffered more attrition than other function words. Hassan Al-Hazeni (2000) selected 60 Saudi military officers who stopped using English for 12 years, and used word test to investigate those officers' English vocabulary attrition. The study showed more than half of the words in the test were attrited.

On the other hand, motivation plays a crucial part in English learning and it also exerts great influence on language attrition. Different types of motivation may affect the degrees of language attrition. Therefore, motivation should be taken into consideration in the study of vocabulary attrition. According to Wlodwoski, motivation is "the process that can arouse and instigate behavior, give direction or purpose to behavior, continue to allow behavior to persist, and lead to choosing or preferring a particular behavior" (1985, p. 2).

\section{MeThodology}

In terms of the research questions, the present study aims to investigate the different types of motivation of students in Nanchong Open University after they have stopped formal English learning for three months, whether the students lost words during the summer vocation significantly, and the influence of different types of motivation on vocabulary attrition. The students participated the two tests are selected from NanChong Open University, more specifically, one hundred and forty eight students from the major of education management and administrative management. All the students are now in grade one, with different ages and different education background. The details of background information of the participants are described in table 1.

Table1. Distribution of the Samples

\begin{tabular}{|l|l|l|l|l|}
\hline \multirow{2}{*}{} & \multicolumn{2}{|l|}{ Gender } & Major & \multicolumn{2}{l|}{} \\
\cline { 2 - 5 } & Male & Female & education management & administrative management \\
\hline $\mathrm{N}$ & 87 & 61 & 52 & 96 \\
\hline Sum & 148 & 148 & \\
\hline
\end{tabular}


With regard to the instruments, the present study is conducted by ways of questionnaire and vocabulary test. The questionnaire includes two sections with one part mainly concerning the background information of the subjects and the other focusing on the different types of motivations. The questionnaire is used twice for the two stages of collecting data. The details of the questionnaire include the name for the purpose of comparing the pre-test and the post-test of the same subjects, gender, major, and grades. In language attrition studies, vocabulary test is the most frequently used method to measure attrition of words. In this study, fifty nouns are randomly selected from Open English book one and two, and so are the fifty verbs. The details of distribution of those words can be seen in table 2.

Table2. Distribution of the Words

\begin{tabular}{|c|c|}
\hline Word Class & N \\
\hline Noun & 50 \\
\hline Verb & 50 \\
\hline Sum & 100 \\
\hline
\end{tabular}

\section{RESULTS AND DISCUSSION}

\subsection{Types of Motivation}

Distribution of motivation types are presented in Table 3. According to the data collected, students have different motivations. Among the three different types, instrumental motivation is the highest motivation owned by one hundred and two participants, which covers a percentage of 68.92among the total subjects. Ten students belong to the cultural motivation type, which accounts for a percentage of 6.76 among the total people. Thirty six students belong to the situational motivation type which occupies 24.32 percent among the total people. From the table, it is obvious that instrumental motivation is the most frequent one among the Open University students.

Table3. Distribution of Motivation Types

\begin{tabular}{|c|c|c|}
\hline motivation types & $\mathrm{N}$ & Percentage \\
\hline Instrumental Motivation & 102 & $68.92 \%$ \\
\hline Cultural Motivation & 10 & $6.76 \%$ \\
\hline Situational Motivation & 36 & $24.32 \%$ \\
\hline Sum & 148 & $100 \%$ \\
\hline
\end{tabular}

In the preceding text, the author stated all the thirty items in that questionnaire were measured by a 5point scale. Table 4 shows the descriptive statistics of different motivation types. Table 4 shows that the mean score, std. deviation and std. error mean of instrumental motivation are respectively 3.9, 1.76, and 0.18. The mean score, std. deviation and std. error mean of cultural motivation are respectively $3.2,1.45$, and 0.48 . The mean score, std. deviation and std. error mean of cultural motivation are respectively $2.4,1.12$, and 0.19 . The mean score, std. deviation and std. error mean of whole motivation are respectively 3.5, 1.62 and 0.14 . The mean of cultural motivation and instrumental motivation are placed the highest among the three while the lowest motivation is cultural motivation. It is further verified that instrumental motivation manifests the strongest of the whole participants while the cultural motivation manifests the weakest.

Table4. Descriptive Analysis for Motivation Types

\begin{tabular}{|c|cc|c|c|c|}
\hline Types & \multicolumn{2}{|c|}{ N Mean } & Std. D & Std.E Mean & df \\
\hline Instrumental Motivation & 102 & 3.9 & 1.76 & 0.18 & 101 \\
\hline Cultural Motivation & 10 & 3.2 & 1.45 & 0.48 & 9 \\
\hline Situational Motivation & 36 & 2.4 & 1.12 & 0.19 & 35 \\
\hline Motivation & 148 & 3.5 & 1.62 & 0.14 & 147 \\
\hline
\end{tabular}

\subsection{Features of Vocabulary Attrition}

The descriptive statistics of the overall words for the two stages are presented in Table 5. As illustrated in the table, the mean score of all the words at stage 1 is 72 while the mean score of all the words at stage 2 is 55 , which shows the score at stage 1 is much higher than the score at stage 2 . The result means that the same participants keep better vocabulary proficiency at stage Ithan stage $\mathbb{I}$. However, whether there exists significant difference between the two stages is not so definitely. Since one of the question of this study is to find out whether the participants experienced significant words attrition after stopping learning English for three months, an paired Sample T-Test is run to answer that question(see Table 6). 
A Study on the Influence of Motivation on Open University Students' Vocabulary Attrition

Table5. Descriptive Statistics of the Overall Vocabulary for the Two Stages

\begin{tabular}{|c|c|c|c|c|}
\hline & N & Mean & Std. Deviation & Std. Error Mean \\
\hline Stage 1 & 100 & 72 & 34.68 & 3.47 \\
\hline Stage 2 & 100 & 55 & 24.37 & 2.44 \\
\hline
\end{tabular}

Table6. Paired-Sample T-Test for the Two Stages

\begin{tabular}{|c|c|c|c|c|c|c|}
\hline & Mean & Std. Deviation & Std. Error Mean & t & df & Sig.(2-tailed) \\
\hline Stage 1-Stage 2 & 17 & 42.39 & 4.24 & 1.99 & 99 & .00 \\
\hline
\end{tabular}

From table 8, the mean, std. deviation and std. error mean are respectively 17, 42.39 and 4.24. The Sig. value is 0.00 , which is lower than the significant difference level of .005 . It means there is statistical significant difference of the scores at the two stages. The result indicates that Open University students experienced significant vocabulary attrition in the past three months of stopping learning English.

\subsection{Effect of Motivation on Vocabulary}

Table 7 shows that the mean score, std. deviation and std. error mean of the group of instrumental motivation at Stage1 are respectively 80, 37.22, and 3.72 while at Stage 2 is 68, 31.54, and 3.15.

The mean score, std. deviation and std. error mean of the Group of cultural motivation at Stage 1 are respectively 69, 32.08 and 10.14 while 48, 37, and 6.77 at Stage 2. The mean score, std. deviation and std. error mean of the Group of situational motivation at Stage 1 are respectively 50, 23.74 and 3.96 while 21, 9.86 and 1.99 at Stage 2. Based on those data, the scores of the words at stage 1 are all higher than stage 2, and the sig value of the groups' instrumental motivation and situational motivation are all lower than the sig value of 0.05 , which shows there is a words decline between the two stages in relation to those groups. However, participants with strong cultural motivation experienced less vocabulary attrition.

Table7. Descriptive Statistics of the Words with Different Motivation Types

\begin{tabular}{|c|c|c|c|c|c|c|c|}
\hline Motivation Types & Stage & $\mathrm{N}$ & Mean & Std. D & Std.EMean & df & sig.(2-tailed) \\
\hline \multirow{3}{*}{ Instrumental Motivation } & Stage 1 & 102 & 80 & 37.22 & 3.72 & 101 & \\
\cline { 2 - 9 } & Stage 2 & 102 & 68 & 31.54 & 3.15 & 101 & \\
\cline { 2 - 9 } & Stage 1-Stage 2 & 102 & 12 & 48.79 & 4.88 & 101 & .012 \\
\hline \multirow{3}{*}{ Cultural Motivation } & Stage 1 & 10 & 69 & 32.08 & 10.14 & 9 & \\
\cline { 2 - 9 } & Stage 2 & 10 & 48 & 21.39 & 6.77 & 9 & \\
\cline { 2 - 9 } & Stage 1-Stage 2 & 10 & 37 & 38.56 & 12.20 & 9 & .06 \\
\hline \multirow{3}{*}{ Situational Motivation } & Stage 1 & 36 & 50 & 23.74 & 3.96 & 35 & \\
\cline { 2 - 9 } & Stage 2 & 36 & 21 & 9.86 & 1.99 & 35 & \\
\cline { 2 - 8 } & Stage 1-Stage 2 & 36 & 29 & 25.71 & 4.29 & 35 & .00 \\
\hline
\end{tabular}

\section{CONCLUSION AND IMPLICATIONS}

From the data, we can reach some conclusion: firstly, for Open University students, there are mainly three types of motivation can be classified. They are instrumental motivation, cultural motivation, and situational motivation respectively. And instrumental motivation is the most frequent one among the Open University students and the cultural motivation manifest the weakest one. Secondly, for Open University students, they experienced significant words attrition after stopping learning English during the summer holiday, and verbs are easier to attrite than nouns. Finally, for Open University students, cultural motivation is proved to retain English words better than the other types of motivation. According to the conclusion, some implications on English teaching and learning can be summarized: to begin with, teachers in Open University should pay more attention to teaching English verbs than nouns, because verbs are more likely to attrite. Next, teachers should also pay attention to long term retaining of English words, but not the immediate English words learning achievements in the learning process of English words. Moreover, the most important thing is to promote Open University students' cultural motivation for the cultural motivation can help resist vocabulary attrition.

\section{REFERENCES}

[1] Freed B F. Language loss: current thought and future directions [A].// Lambent R D, Freed, B F, The lass of language skills. Rowley, MA: Newbury House, 1982: 207-223.

[2] Hassan A1-Hazemi. 2000. Lexical Attrition of Some Arabic Speakers of English as a Foreign language: A Study of Word Loss[J]. The Internet TESL Journal 5(12).

[3] Olshtain, Elite. 1989. Is second language attrition the reversal of second language acquisition? [J] SSLA, 11, 151-165. 
[4] Wlodwoski, R. J. (1985). Enhancing adult motivation to learn. San Francisco: Jossey-Bass.

[5] 倪传斌 情感因素对外语磨蚀群体目标语接触量的影响一基于数据挖掘的建模与分类 [J]. 外语教学理论与实践, 2010(1).

[6] 高一虹、赵媛、程英、周燕, 中国大学本科生英语学习动机类型 [J]. 现代外语(季刊), 2003(1).

\section{AUTHORS' BIOGRAPHY}

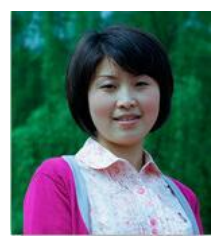

Yu Huang,

Lecturer from The open University of China, study in English Language teaching.

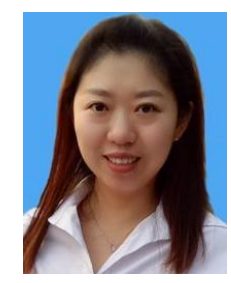

\section{Zhou Shu,}

Lecturer, from the College of Foreign Language Education in China West Normal University, Study in English teaching and Curriculum. 